\section{Cataract surgery: who and how much?}

The problem of cataract measurement is not trivial. Simple observation of a poorly sighted eye has for many centuries been used by physicians and lay people for the diagnosis of cataract. Improved illumination, magnification and pupil dilatation have allowed more accurate assessment, with loupes, ophthalmoscopes, and slit-lamp biomicroscopes providing opportunities for improved diagnostic precision. The desire for a complete knowledge of the physical and optical characteristics of lens changes has encouraged greater refinement of cataract measurement. Detailed classification and grading schemes based on recognised clinicopathological lens features have been developed in which cataracts are initially classified into subtypes which are then separately quantified to provide a set of numeric scores. By comparative observation, standard reference diagrams or photographs act as 'milestones' which locate fixed points along a scale of severity for each subtype. With attention to relevant aspects of measurement theory, grading systems have evolved to high levels of performance. ${ }^{1,2}$ The recent wave of technological advancement has not ignored cataract assessment, with Scheimpflug and retro-illumination imaging, digital image analysis, in vivo light scattering, lens transmittance, fluorescence studies, magnetic resonance imaging and confocal laser scanning microscopy all claiming a place. Automated techniques can have impressively high levels of reliability. ${ }^{3}$ Vision-based indirect measures of cataract are also well established. Traditional high-contrast Snellen acuity values are being replaced by better-designed LogMAR scales, and contrast sensitivity, glare disability, stereoacuity, Vernier acuity and the Pulfrich phenomenon have also been proposed for cataract assessment.

In contrast to the energy devoted to the technological approach, the patient's experience of cataract has until recently received little attention. Poor vision is for some people much more unpleasant than for others. A group of individuals with the same level of visual impairment may exhibit widely varying levels of physical, social and emotional disturbance because of varying needs, attitudes and environments. Variation due to these factors will never be predicted accurately by observing lens changes or by performing vision assessments, regardless of the number of tests employed. For these reasons there is growing awareness of the importance of quality of life assessment in judging the need for surgery. 4,5

Pioneering work in this area of research was performed by Bernth-Petersen ${ }^{6}$ and now there are numerous available vision questionnaires based on visual symptoms and physical function such as the one used by Monestam and Wachtmeister. ${ }^{7}$ The next challenge in needs assessment is to move beyond these measures of physical function. It is uncertain whether physical symptom or physical function questionnaires can be used to demonstrate a need for ophthalmic intervention, because an individual with visual impairment may find the particular symptoms or activities covered irrelevant to their own situation or may not be concerned by their impairment. For example, not all patients with low vision express a wish to improve their eyesight 'in order to watch television'. ${ }^{8}$ In contrast, the importance of psychological and social issues in visual impairment has long been recognised and it is clear that assessment of physical function provides an incomplete description of visionrelated quality of life impairment. ${ }^{9}$ The WHOQOL group argues that although the person's report of functioning is important information, it is more global questions that inform about quality of life. ${ }^{10}$ Other researchers have also concluded that it may not be appropriate to require specific functional limitations as a precondition for cataract surgery and have suggested the use of more general questions. ${ }^{11}$

Quality of life assessment provides a valuable additional insight into the effectiveness of cataract surgery and may still show improvement when traditional measures of visual outcome are poor, ${ }^{12}$ such as in cases with severe ocular co-morbidity. ${ }^{8}$ In second eye surgery, where vision with both eyes open is already good, substantial added benefit may be detectable. ${ }^{13}$ On the other side, quality of life assessment may reveal poor effectiveness in an uncomfortably large number of cases. ${ }^{14}$ Despite resource limitations it is possible for certain individuals to be 'caught up in the flow' of a health provision system, and to receive surgery when there may be uncertainty about its value. A study in Norway found that one of every six patients listed for cataract surgery felt their

\author{
J.M. Sparrow \\ N.A. Frost \\ Bristol Eye Hospital \\ Bristol, UK
}

Mr John M. Sparrow Bristol Eye Hospital Lower Maudlin Street Bristol BS1 2LX, UK

Fax: $+44(0) 1179251421$ 
visual problems to be so small that the operation was not presently needed. ${ }^{15}$ In Manitoba (Canada), Denmark, Barcelona (Spain) and the United States the percentages of pre-operative patients who reported no trouble with their vision ranged from $2 \%$ to $4.6 \%{ }^{16}$

Globally cataract is the commonest cause of blindness, and in developed nations cataract surgery is one of the commonest surgical procedures. Improved surgery, raised patient expectations and demographic shifts all point in the direction of increasing demand. A detailed understanding of the impact of cataract on the lives of those affected is essential to rational judgements about surgical provision for cataract. The study of ophthalmic needs and outcomes assessment is in its infancy, and present work highlights the challenges which lie ahead. In this issue, Monestam and Wachtmeister ${ }^{7}$ have provided a valuable contribution to the debate on cataract surgical provision by detailing the characteristics of a surgical cohort drawn from a geographically discrete population.

\section{References}

1. Sparrow JM, Frost NA, Pantelides E, Laidlaw DAH. Decimalisation of the Oxford Clinical Cataract Classification and Grading System. Ophthalmic Epidemiol 1999; in press.

2. Chylack LTJ, Wolfe JK, Singer DM, et al. The Lens Opacities Classification System III. Arch Ophthalmol 1993;111:831-6.

3. Garrett SK, Robman LD, McCarty CA, Thomas AP, McNeil JJ, Taylor HR. Reproducibility of automatic standard digital analysis of lens opacities. Aust NZ J Ophthalmol 1998;26(Suppl 1):S29-31.

4. American Academy of Ophthalmology Preferred Practice Patterns Committee: Anterior segment panel, ed. Preferred practice pattern: Cataract in the adult eye. San Francisco: American Academy of Ophthalmology, 1996.
5. The Royal College of Ophthalmologists. Guidelines for cataract surgery. London: Royal College of Ophthalmologists, 1995.

6. Bernth-Petersen P. Cataract surgery: outcome assessments and epidemiologic aspects. Acta Ophthalmol (Copenh) 1985;63 (Suppl 174):1-47.

7. Monestam E, Wachtmeister L. Impact of cataract surgery on visual acuity and subjective functional outcomes: a population-based study in Sweden. Eye 1999;13:??-??.

8. Monestam E, Wachtmeister L. The impact of cataract surgery on low vision patients: a population based study. Acta Ophthalmol Scand 1997;75:569-76.

9. Frost NA, Sparrow JM, Durant JS, Donovan JL, Peters TJ, Brookes ST. Development of a questionnaire for measurement of vision-related quality of life. Ophthalmic Epidemiol 1998;5:185-210.

10. The WHOQOL Group. The World Health Organisation Quality of Life Assessment (WHOQOL): Position paper from the World Health Organisation. Soc Sci Med 1995;41:1403-9.

11. Kington R, Rogowski J, Lillard L, Lee PP. Functional associations of 'trouble seeing'. J Gen Intern Med 1997;12:125-8.

12. Desai P, Reidy A, Minassian DC, Vafidis G, Bolger J. Gains from cataract surgery: visual function and quality of life. Br J Ophthalmol 1996;80:868-73.

13. Laidlaw DAH, Harrad RA, Hopper CD, et al. Randomised trial of effectiveness of second eye cataract surgery. Lancet 1998;352:925-9.

14. Mangione CM, Orav EJ, Lawrence MG, Phillips RS, Seddon JM, Goldman L. Prediction of visual function after cataract surgery: a prospectively validated model. Arch Ophthalmol 1995;113:1305-11.

15. Sletteberg O, Hovding G, Bertelsen T. Do we operate too many cataracts? The referred cataract patients' own appraisal of their need for surgery. Acta Ophthalmol (Copenh) 1995;73:77-80.

16. Alonso J, Espallargues M, Andersen TF, et al. International applicability of the VF14: an index of visual function in patients with cataracts. Ophthalmology 1997;104:799-807. 